\title{
ABORDAGEM NÚMERICA PRELIMINAR DO ARRASTE DE SÓLIDOS EM CÉLULAS COMBUSTÍVEIS MICROBIANAS DE LEITO FLUIDIZADO
}

\author{
R. B. BASTOS ${ }^{1}$, G. V. B., MONTZEL ${ }^{1}$, E. ROSA SILVA ${ }^{1}$, C. S. OGRODOWSKI ${ }^{1}$ e F. B. \\ SANTANA $^{1}$
}

1 Universidade Federal do Rio Grande - FURG, Escola de Química e Alimentos - EQA E-mail para contato: eduardodarosasilva@gmail.com

\begin{abstract}
RESUMO - Células combustíveis microbianas (CCM) são dispositivos que utilizam bactérias para converter a energia química presente na matéria orgânica em energia elétrica. Dentre as diferentes geometrias de CCM destacam-se as CCMs de leito fluidizado. Neste dispositivo, o eletrodo é constituído de grafite particulado, aumentando assim sua superfície. Objetivando otimizar o potencial deste reator, a fluidodinâmica computacional (CFD) se torna uma útil ferramenta para estudar os parâmetros do projeto. Assim, o objetivo deste trabalho foi modelar e simular o arraste de sólidos proveniente da interação líquido-partícula em uma CCM. Para isto, foi construido um reator experimental que foi operado em vazão constante de $500 \mathrm{ml} / \mathrm{min}$, analisando a vazão de saída de sólidos. Também foi elaborado um modelo numérico e sua respectiva simulação fluidodinâmica. Os resultados experimentais foram utilizados para validação do modelo que foi simulado no software FLUENT 14.5. Foi utilizado abordagem euleriana-euleriana de duas fases (líquida e sólida granular). Na fase granular foram aplicadas as equações constituintes da teoria cinética granular. O melhor refino de malha foi o de 30739 células, e o modelo apresentou uma boa acurácia quando comparado com os resultados experimentais com erro absoluto médio de $0,98 \%$.
\end{abstract}

\section{INTRODUÇÃO}

A demanda energética mundial promove a crescente busca por alternativas às fontes convencionais de energia elétrica. Ademais, os impactos ambientais associados à produção desta devem ser considerados. Por esses motivos, uma ascendente tecnologia denominada Célula Combustível Microbiana (CCM) se destaca. Seu processo de geração de energia está associado ao tratamento do efluente utilizado, uma vez que, ao converter energia química em energia elétrica, oxida o conteúdo orgânico através da ação de micro-organismos. Entretanto, seu potencial pode ser influenciado por diversos fatores. Dentre esses, a configuração estrutural é um dos aspectos cruciais para a eficiência do processo, visto que interfere diretamente nas interações que ocorrem entre os micro-organismos e a matéria orgânica. O modelo mais comum de uma CCM possui duas câmaras, anódica e catódica, separadas por uma membrana que permite a passagem de cátions, conforme descrito por Logan et al. (2006).

Outro exemplo de geometria é a CCM de leito fluidizado, cuja construção promove o 


\section{Congresso Brasileiro de Engenharia Química \\ em Iniciação Científica \\ UFSCar - São Carlos - SP \\ 16 a 19 de Julho de 2017}

aumento do potencial elétrico gerado em comparação a outros modelos de CCM, uma vez que sua estrutura intensifica a transferência de massa e a superfície de carga do eletrodo de acordo com o trabalho de Wang et al. (2014).

\section{FLUIDODINÂMICA COMPUTACIONAL: ESCOAMENTO MULTIFÁSICO}

Escoamento multifásico é todo aquele sistema onde há interação de duas ou mais fases diferentes, sejam elas líquida/sólida, líquida/gasosa, gasosa/sólida ou duas fases líquidas imiscíveis. Um dos métodos mais utilizados para este tipo de modelo é a abordagem eulerianaeuleriana, esta considera as duas fases contínuas, interpenetrantes e dividindo uma única pressão (Coroneo et al., 2011). Tal abordagem insere o conceito de fração volumétrica de fase, onde o somatório das frações de cada fase é igual a 1.

Então, para cada fase é aplicada e resolvida a equação da continuidade, através da Equação 1, e a equação da conservação de quantidade de movimento através da Equação 2.

$$
\begin{aligned}
& \frac{\partial\left(\alpha_{q} \rho_{q}\right)}{\partial t}+\nabla \cdot\left(\alpha_{q} \rho_{q} \vec{v}_{q}\right)=\sum_{p=1}^{n}\left(m_{p q}-m_{q p}\right)+S_{q} \\
& \frac{\partial\left(\alpha_{q} \rho_{q}\right)}{\partial t}+\nabla \cdot\left(\alpha_{q} \rho_{q} \vec{v}_{q} \vec{v}_{q}\right)=-\alpha_{q} \nabla P+\nabla \cdot \bar{\tau}_{q}+\alpha_{q} \rho_{q} \vec{g}+\sum_{p=1}^{n}\left(\vec{R}_{p q}+m_{p q} \vec{v}_{p q}-m_{q p} \vec{v}_{q p}\right)+\left(\vec{F}_{q}+\vec{F}_{s u s t, q}+\vec{F}_{m v, q}\right)
\end{aligned}
$$

O termo $\vec{R}$, definido como a transferência de movimento entre as fases é definido através da Equação 3.

$$
\vec{R}=K_{s f}\left(\vec{v}_{s}-\vec{v}_{l}\right)
$$

A constante $\mathrm{K}_{\mathrm{sf}}$ é definida como o coeficiente de troca de movimento entre as fases, tal termo pode ser calculado através do modelo de Gidaspow et al. (1992). Este modelou o parâmetro através de duas equações, o uso das mesmas é definido pela fração volumétrica da fase contínua. Se o volume do líquido tiver uma fração maior que 0,8 o termo é calculado através da definição de Wen e Yu (1966). Caso seja menor que 0,8 a constante é definida pelo modelo de Ergun (1952).

Quando a abordagem euleriana é aplicada a fases sólidas, equações complementares devem ser resolvidas para adaptar um meio discreto e granular a um sistema contínuo. Estas equações são provenientes da Teoria Cinética Granular, apresentada por Lu et al. (1984). Para tal, é inserido o conceito de temperatura granular, que é a medida das flutuações de velocidade da fase sólida, devido a isso, um novo balanço é requerido, o balanço de temperatura granular. Através desta teoria, é também calculada a pressão de sólidos (Lun et al., 1984) e viscosidade para a fase sólida (Symlal e O’Brien, 1993; Lun et al., 1993 e Schaeffer, 1987).

Desse modo, o objetivo deste trabalho foi modelar e simular o arraste de sólidos proveniente 


\section{Congresso Brasileiro de Engenharia Química \\ em Iniciação Científica \\ UFSCar - São Carlos - SP \\ 16 a 19 de Julho de 2017}

da interação líquido-partícula em uma CCM analisando a influência do modelo de transferência de momento entre as fases de Gidaspow et al. (1992). Para isso, um estudo de refino de discretização aplicado, juntamente com uma validação experimental.

\section{PROCEDIMENTO EXPERIMENTAL}

O modelo físico referente à câmara anódica da CCM, conforme é mostrado na Figura 1, é constituído por, externamente, duas luvas de redução 50 x $25 \mathrm{~mm}$ de PVC soldáveis com $70 \mathrm{~mm}$ de altura e uma membrana CMI - 7000S com diâmetro de $50 \mathrm{~mm}$ e $150 \mathrm{~mm}$ de altura. Além disso, o reator possui um cilindro de vidro com $24 \mathrm{~mm}$ de diâmetro e $400 \mathrm{~mm}$ de altura, posicionado concêntrico às paredes do reator. Por fim, foram adicionados suportes internos para garantir a fixação das partes da estrutura.

Figura 1 - Modelo físico da câmara anódica da CCM de tubos concêntricos

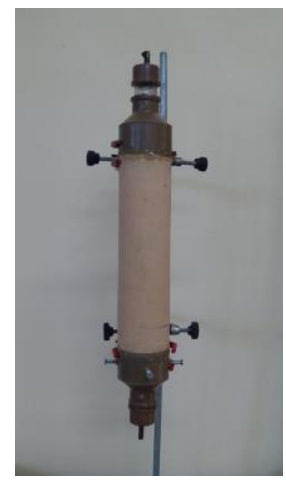

Foram adicionados $200 \mathrm{~g}$ de partículas de grafite com diâmetro médio de $0,7 \mathrm{~mm}$ no reator, formando um leito compactado de $134 \mathrm{~mm}$ de altura. Posteriormente, o volume do reator foi completado com água em vazão baixa através da entrada da base do reator, visando evitar o movimento das partículas. Os testes foram executados com uma bomba peristáltica adicionando água à temperatura ambiente na velocidade de $0,0169 \mathrm{~m} / \mathrm{s}$ na base do reator por $30 \mathrm{~s}$, o que gera uma vazão de $500 \mathrm{ml} / \mathrm{min}$. A vazão de saída (líquido + sólido) foi coletada em intervalos de $3 \mathrm{~s}$ para posterior avaliação da massa de sólido arrastada. O sólido foi mensurado através de gravimetria, realizada em estufa sem recirculação de ar à temperatura de $105^{\circ} \mathrm{C}$.

\section{MODELO COMPUTACIONAL}

\section{1 - Geometria, discretização e condições de contorno}

Para a execução das simulações, a geometria foi reproduzida no software Gambit 2.4.6. Para o teste de refinamento de malha foram criadas cinco malhas quadradas com 7925, 13918, 21197 , 30739 e 37919 células cada. As simulações foram executadas utilizando o software FLUENT 14.5 utilizando abordagem euleriana-euleriana e as condições utilizadas na batelada experimental. $\mathrm{O}$ modelo de transferência de momento entre fases utilizado para essa validação foi o de Gidaspow et al. (1992). O passo de tempo utilizado foi de 0,0005 s. A malha selecionada foi a que apresentou menor acumulo de erro $( \pm 1 \%)$. As condições de contorno foram definidas conforme indicado na Figura 2. Nesta, o orifício da base do reator é a entrada de velocidade; a parede localizada após o tubo de vidro é a saída de pressão; eixo axisssimétrico no centro reator, visto 


\section{Congresso Brasileiro de Engenharia Química \\ em Iniciação Científica \\ UFSCar - São Carlos - SP \\ 16 a 19 de Julho de 2017}

CONGRESSO BRASILEIRO DE ENGENHARIA

que, por ser simétrico, permite replicar os resultados obtidos em metade do reator para um todo, diminuindo a demanda computacional; por fim, as outras bordas do modelo foram definidas como paredes com condição de aderência.

Figura 2 - Condições de contorno do modelo

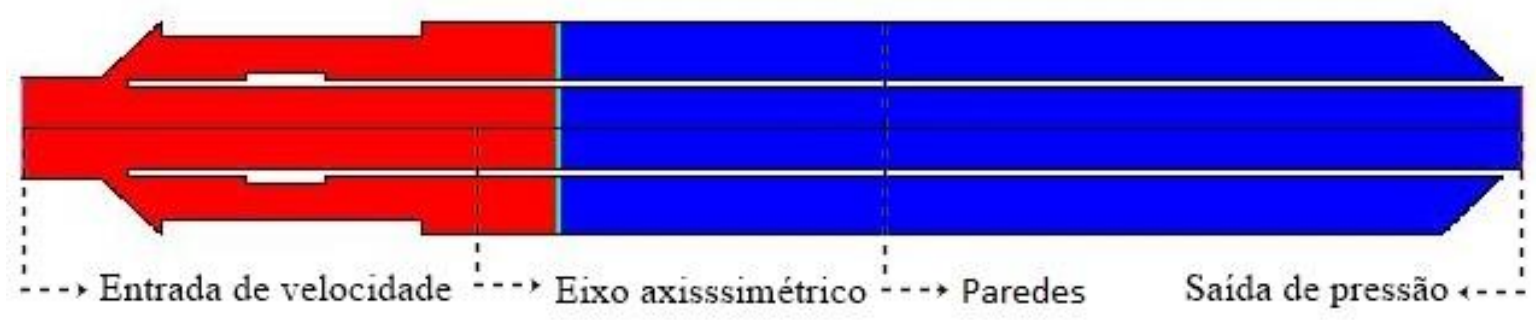

\section{RESULTADOS E DISCUSSÕES}

Os resultados referentes à validação de independência de malhas estão representados na Figura 3, onde foram comparadas as massas de grafite retidas no reator quando submetido a mesma vazão. A malha que apresentou o menor acúmulo de erro durante as iterações em comparação com outra malha foi a com espaçamento 0,5, ou seja, 30739 células. Foi observado erro inferior a 1\% em relação a malha de 37919 células.

Figura 3 - Validação da independência de malhas pelo modelo de Gidaspow

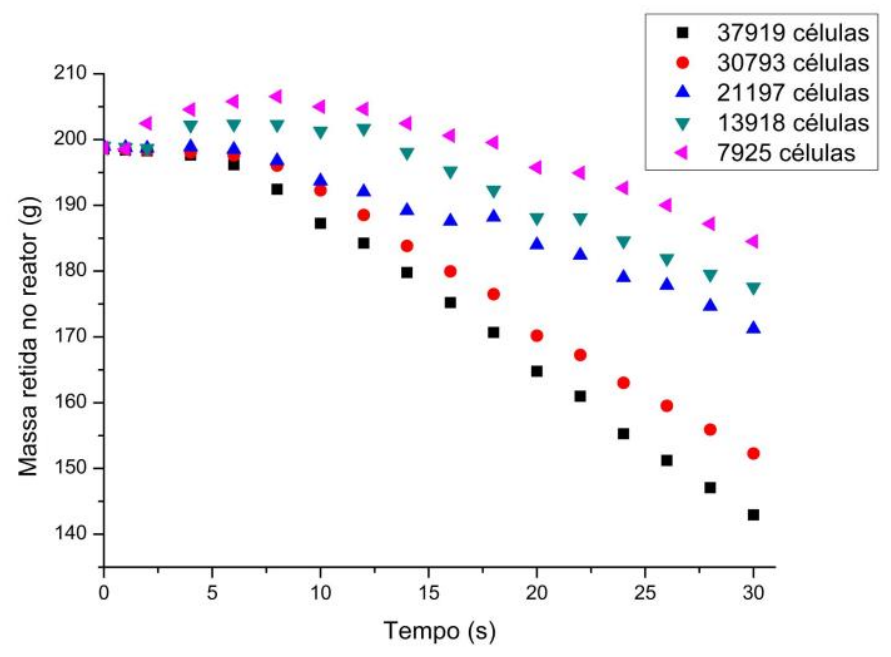

A validação do modelo de transferência de momento entre fases em comparação aos resultados experimentais está representada pela Figura 4a. O ponto de inflexão na curva experimental entre 20 e 25 s pode ser justificado pelo rompimento de leito. A Figura $4 \mathrm{~b}$ apresenta o erro absoluto observado. O erro médio de $0,98 \%$ foi baixo e observa-se um comportamento não tendecioso no acúmulo do erro, corroborando a validação do modelo e de quantidade de células utilizadas. A movimentação do sólido observada na simulação é apresentada na Figura 5, primeiramente em seu momento inicial e logo após em um tempo intermediário do arraste. É possível observar o arraste do particulado através do tubo interno, enquanto o externo retém grande parte das partículas. 


\section{Congresso Brasileiro de Engenharia Química \\ em Iniciação Científica \\ UFSCar - São Carlos - SP

Figura 4 - Validação do modelo e erros absolutos

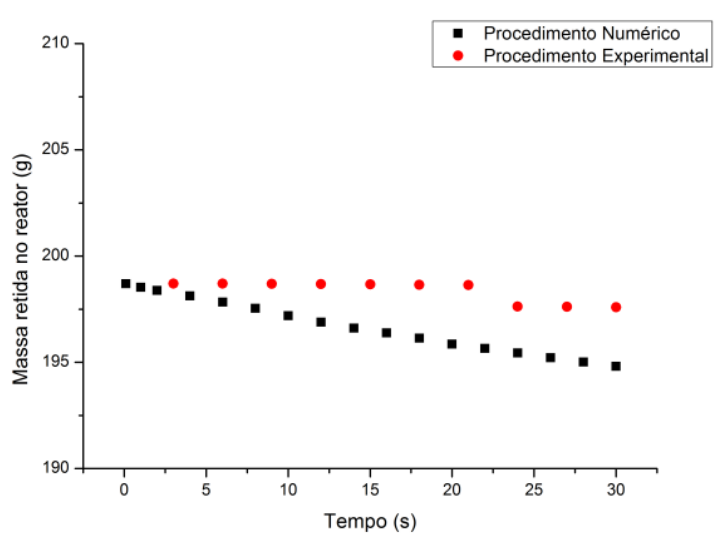

(a)

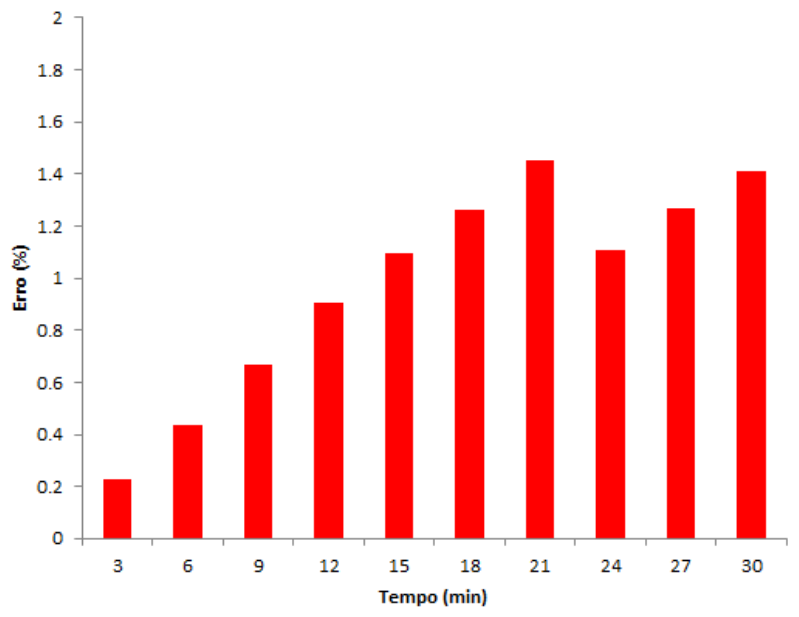

(b)

Figura 5 - Arraste do sólido simulado
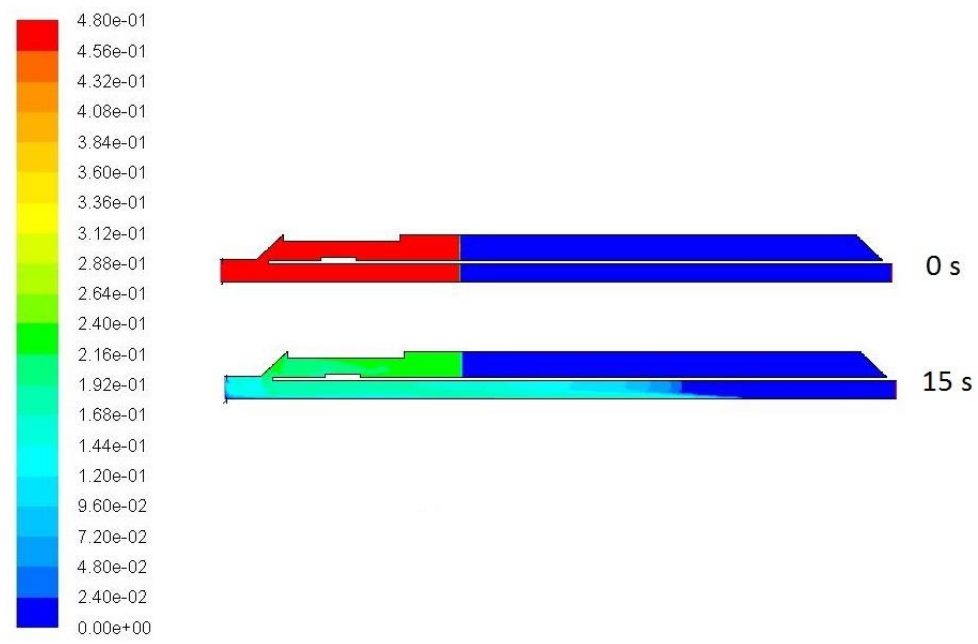

\section{CONCLUSÕES}

Nas condições propostas, o arraste do sólido foi coerente quando comparado aos dados experimentais com os numéricos. A discrepância observada pode ser justificada pela quebra das partículas de grafite que não é considerada no modelo. Outro motivo é o uso de apenas um diâmetro médio no modelo numérico, enquanto, na verdade, o grafite apresenta outros tamanhos em menores frações, caracterizando uma distribuição de partícula heterogênea com formação de aglomerados e ocorrência de quebras. Para trabalhos futuros podem ser abordados o tempo de residência, a otimização da geometria, a implementação de balanços populacionais na fase sólida e a adição do topo do reator ao modelo, com a devida recirculação da partícula. 


\section{NOMENCLATURA}

\begin{tabular}{|c|c|c|}
\hline Símbolo & Definição & Unidade \\
\hline$\alpha_{\mathrm{q}}$ & Fração volumétrica da fase $\mathrm{q}$ & - \\
\hline$\rho_{\mathrm{q}}$ & Massa específica da fase $q$ & $\mathrm{~kg} / \mathrm{m}^{3}$ \\
\hline$\overline{\bar{\tau}}$ & Tensor tensão & $\mathrm{Pa}$ \\
\hline$\nabla \mathrm{P}$ & Gradiente de pressão; & $\mathrm{Pa}$ \\
\hline $\overrightarrow{\mathrm{F}}$ & Forças de corpo; & $\mathrm{N}$ \\
\hline & Forças de sustentação; & $\mathrm{N}$ \\
\hline & Forças de massa virtual; & $\mathrm{N}$ \\
\hline $\overrightarrow{\mathrm{g}}$ & Gravidade; & $\mathrm{m} / \mathrm{s}^{2}$ \\
\hline $\mathrm{K}_{\mathrm{sf}}$ & Coeficiente de troca de movimento entre as fases & $\mathrm{kg} / \mathrm{m}^{2} \mathrm{~s}^{2}$ \\
\hline $\mathrm{m}_{\mathrm{pq}}$ & Transferência de massa da fase p para a fase q; & $\mathrm{kg}$ \\
\hline $\mathrm{m}_{\mathrm{qp}}$ & Transferência de massa da fase $\mathrm{q}$ para a fase $\mathrm{p}$ & $\mathrm{kg}$ \\
\hline $\overrightarrow{\mathrm{R}}_{\mathrm{p}}$ & Transferência de movimento entre fases p e q; & $\mathrm{kg} / \mathrm{m} . \mathrm{s}$ \\
\hline $\mathrm{S}_{\mathrm{q}}$ & Geração ou sumidouro de massa; & $\mathrm{kg} / \mathrm{m}^{3} \mathrm{~s}$ \\
\hline $\mathrm{V}$ & Volume da fase; & $\mathrm{m}^{3}$ \\
\hline $\overrightarrow{\mathrm{v}}_{\mathrm{i}}$ & Velocidade da fase; & $\mathrm{m} / \mathrm{s}$ \\
\hline $\overrightarrow{\mathrm{v}}_{\mathrm{pc}}$ & Velocidade da transferência de massa entre as fases. & $\mathrm{m} / \mathrm{s}$ \\
\hline
\end{tabular}

\section{REFERÊNCIAS}

CORONEO, M.; MAZZEI, L.; LETTIERI, P.; PAGLIANTI, A.; MONTANTE, G. CFD prediction of segregating fluidized bidisperse mixtures of particles differing in size and density in gas-solid fluidized beds. Chem. Eng. Sci., v. 66, p. 2317-2327, 2011.ERGUN, S. Fluid Flow through Packed Columns. Chem. Eng. Prog, v. 48, p. 8994, 1952.

GIDASPOW, D.; BEZBURUAH, R.; DING, J. Hidrodynamics of Circulating Fludized Beds: Kinect Theory Approach. 7th Fluidizations Congress. Chicago, EUA, 1992.

LOGAN, B. E.; HAMELERS, B.; ROZENDAL, R.; SCHRÖDER, U.; KELLER, J.; FREGUIA, S.; AELTERMAN, P.; VERSTRAETE, W.; RABAEY, K. Microbial fuel cells: methodology and technology. Environ. Sci. Technol., v. 40, p. 5181-5192, 2006.

LUN, B. C. K. K.; SAVAFE, S. B.; JEFFREY, D. J. Kinetic theories for granular flow: inelastic particles in Couette flow and slightly inelastic particles in a general flowfield. J. Fluid Mech., v. 140 p. 223-256, 1984.

SCHAEFFER, D. G. Instability in the evolution equations describing incompressible granular flow. J. Differ. Equations, v. 66, p. 19-50, 1987.

WANG, X.; YUE, X.; GUO, Q. Production of Electricity during Wastewater Treatment Using Fluidized-Bed Microbial Fuel Cells. Chem. Eng. Technol., v. 37, p. 703-708, 2014.

WEN, C. Y.; YU, Y.W. Mechanics of Fluidization. Chem. Eng. Prog. Symp. Ser., 1966. 